\title{
Deficiency of Gpr1 improves steroid hormone abnormality in hyperandrogenized mice
}

\author{
Ya-Li Yang ${ }^{1 \dagger}$, Li-Feng Sun ${ }^{1,2+}$, Yan Yu ${ }^{3 \dagger}$, Tian-Xia Xiao ${ }^{1}$, Bao-Bei Wang ${ }^{1}$, Pei-Gen Ren ${ }^{1}$, Hui-Ru Tang ${ }^{4 *}$
} and Jian V. Zhang ${ }^{*}$

\begin{abstract}
Background: Polycystic ovary syndrome (PCOS) is a complex genetic disease with multifarious phenotypes. Many researches use dehydroepiandrosterone (DHEA) to induce PCOS in pubertal mouse models. The aim of this study was to investigate the role of GPR1 in dehydroepiandrosterone (DHEA)-induced hyperandrogenized mice.

Methods: Prepubertal C57BL/6 mice (25 days of age) and Gpr1-deficient mice were each divided into two groups and injected daily with sesame oil with or without DHEA $(6 \mathrm{mg} / 100 \mathrm{~g})$ for 21 consecutive days. Hematoxylin and eosin (H\&E) staining was performed to determine the characteristics of the DHEA-treated ovaries. Real-time PCR was used to examine steroid synthesis enzymes gene expression. Granulosa cell was cultured to explore the mechanism of DHEA-induced, GPR1-mediated estradiol secretion.

Results: DHEA treatment induced some aspects of PCOS in wild-type mice, such as increased body weight, elevated serum testosterone, increased number of small, cystic, atretic follicles, and absence of corpus luteum in ovaries. However, Gpr1 deficiency significantly attenuated the DHEA-induced weight gain and ovarian phenotype, improving steroidogenesis in ovaries and estradiol synthesis in cultured granulosa cells, partially through mTOR signaling.

Conclusions: In conclusion, Gpr1 deficiency leads to the improvement of steroid synthesis in mice hyperandrogenized with DHEA, indicating that GPR1 may be a therapeutic target for DHEA-induced hyperandrogenism.
\end{abstract}

Keywords: GPR1, Hyperandrogenism, Steroidogenesis, Estradiol

\section{Background}

Dehydroepiandrosterone (DHEA) is the most abundant steroid in human blood circulation. Synthesized mainly in the adrenal zona reticularis [1], it is an important precursor in follicular steroidogenesis and plays roles in protecting the central nervous system, preventing neurodegenerative diseases [2], improving depression [3], regulating and stabilizing inflammation and cellular immune functions [4], improving blood lipid metabolism

\footnotetext{
* Correspondence: 13828857955@126.com; jian.zhang@siat.ac.cn

${ }^{+}$Ya-Li Yang, Li-Feng Sun and Yan Yu contributed equally to this work.

${ }^{4}$ Peking University Shenzhen Hospital, Shenzhen 518035, China

${ }^{1}$ Research Laboratory for Reproductive Health, Shenzhen Institutes of Advanced Technology, Chinese Academy of Sciences, Shenzhen 518055, China

Full list of author information is available at the end of the article
}

[5], preventing osteoporosis [6], and protecting the cardiovascular system [7]. Since DHEA can be converted to androgens and estrogens, high levels of DHEA have been found to affect ovarian folliculogenesis [8] and lipid metabolism [9].

DHEA is generally increased in women with polycystic ovary syndrome (PCOS) [10]. PCOS is the most common and complex endocrine disorder affecting women of reproductive age and is characterized by hyperandrogenemia, menstrual irregularities, anovulation, infertility, obesity and hirsutism [11]. Women with PCOS are also at high risk of developing diabetes, insulin resistance, metabolic dysfunction, glucose intolerance, and cardiovascular disease [12].

(c) The Author(s). 2018 Open Access This article is distributed under the terms of the Creative Commons Attribution 4.0 International License (http://creativecommons.org/licenses/by/4.0/), which permits unrestricted use, distribution, and reproduction in any medium, provided you give appropriate credit to the original author(s) and the source, provide a link to the Creative Commons license, and indicate if changes were made. The Creative Commons Public Domain Dedication waiver (http://creativecommons.org/publicdomain/zero/1.0/) applies to the data made available in this article, unless otherwise stated. 
Owing to the heterogeneous presentations of PCOS, it is difficult to develop an animal model that could mimic all the phenotypes observed in clinical. To date, PCOSlike animal model could be established by several approaches. Androgen-induced rodent PCOS models, based on DHEA, DHT or testosterone- present hyperandrogenemia, anovulation, cystic ovaries and development of impaired insulin/glucose metabolism [13]. Estrogeninduced rodent PCOS models, using estradiol benzoate, E2 and E2 valerate- can result in polycystic ovaries and anovulation but lack of metabolic features associated with human PCOS [14]. Aromatase inhibitor-letrozoleinduced rodent PCOS models can cause ovulatory failure and polycystic ovaries [15]. And some chemicals, such as RU486, a progesterone receptor antagonist which inhibits the development and maturation of follicles, can result in delayed ovulation and induction of hyperprolactinemia like PCOS [16]. Besides, environmental influences, such as high fat diet [17], excess soy [18] and light, may also induce PCOS characteristics especially related metabolic co-morbidities. In addition, Transgenic modifications, such as the overexpression of NGF (nerve growth factor) in the ovary [19] or the overexpression of PAI-1(plasminogen activator inhibitor-1) in the ovary could cause PCOS in mice. Comparatively, among these approaches above, the most common PCOS models are based on hyperandrogenism induced pre-/post-natal stage or adulthood, since it is generally believed that increased androgen level is the main cause of PCOS [20].

Many researches use DHEA to induce PCOS in pubertal mouse models. Mice treated with DHEA are infertile, and their ovaries contain more cystic and atretic follicles and lack corpus luteum. Serum hormone levels, metabolic parameters, and inflammatory signals are also changed after DHEA treatment [21-23]. Whether DHEA treatment in rodents is an ideal approach to mimic human PCOS is still uncertain; however, the results of many studies indicate that postnatal treatment of mice with DHEA induces at least some aspects of PCOS, such as bodyweight gain, elevated serum insulin and glucose and more atretic follicles [20].

Chemerin is both a chemokine and an adipokine and plays important roles in immune responses, inflammation, adipogenesis, and carbohydrate metabolism [24]. Clinical data have shown that serum Chemerin levels are increased in women with PCOS and decrease after metformin treatment [25], indicating that Chemerin may be involved in the development of the metabolic disorders associated with PCOS. Our previous research has shown that Chemerin inhibits gonad hormone secretion from testes and ovaries [26].

So far, three endogenous receptors for Chemerin have been identified: GPR1, CMKLR1, and CCRL2 [24]. Among these, CCRL2 has not been shown to transduce the Chemerin signal but may increase local Chemerin concentration and affect inflammation via CMKLR1 [27]. CMKLR1 is the most well-characterized Chemerin receptor, and most of the biological functions of Chemerin have been shown to depend on CMKLR1 activation [28]. Our recent study showed that CMKLR1 gene deletion attenuates the effects of chronic DHT treatment on ovarian function in experimental PCOS [29]. Although Chemerin is the only known ligand for GPR1, few functions have been suggested for GPR1. It has been reported that GPR1 is expressed in metabolically active tissues and plays a functional role in glucose homoeostasis in obesity [30]. A new study from our lab shows that Chemerin and GPR1 are expressed in the mouse ovary during the estrous cycle and that Chemerin/GPR1 signaling could suppress hCG-induced progesterone synthesis and secretion during follicle development, partly through PI3K [31].

Whether GPR1 plays a regulatory role in hormone secretion and metabolism in hyperandrogenic mice is still unknown; there have been no previous reports on the relationship between the Chemerin receptor GPR1 and hyperandrogenism. Here we compare wild-type and Gpr1 knockout mice in our model of DHEA-induced hyperandrogenism to explore the role of GPR1 in bodyweight, steroidogenesis and metabolism.

\section{Methods \\ Animals}

Gpr1 knockout mice in the C57BL/6 J background were provided by Deltagen Ltd. and the Zabel lab, the validations for Gpr1 knockout mice were shown in an (Additional file 1: Figure S1). C57BL/6 J wild type female mice were obtained from the Laboratory Animal Center, Institutes of Biomedicine and Health, Chinese Academy of Sciences, China. Mice were maintained under standard housing conditions with controlled temperature and humidity, a 12-h lightdark cycle, and ad libitum access to food and water. All procedures related to animal use were approved by the Committee on the Use of Live Animals for Teaching and Research, Shenzhen Institutes of Advanced Technology, Chinese Academy of Sciences.

\section{Establishment of DHEA-induced hyperandrogenic mice} Pre-pubertal C57BL/6 mice (25 days of age) and Gpr1 knockout mice were each divided into two groups (control and DHEA; 6 per group) and injected subcutaneously daily with sesame oil or sesame oil with DHEA (6 mg/100 g) for 21 consecutive days (Hubei Danjiangkou Kaitai Hormone CO., LTD). Body weights were determined every 3 days during treatment. At the end of the treatment period, mice were anesthetized and blood samples were collected by removal of the eyeballs. Mice were then euthanized by 
cervical dislocation, and tissues were collected. Aliquots of serum samples were sent to the Beijing North Institute of Biological Technology (Beijing, China) to measure levels of estradiol, progesterone, and testosterone. Separate aliquots of serum were sent to Shenzhen SHAHE Hospital (Shenzhen, China) to measure serum lipids. Hypothalamus and pituitary glands were isolated and stored in RNAiso Plus (Takara Bio) at $80{ }^{\circ} \mathrm{C}$ for subsequent total RNA isolation. Ovaries and fat tissues were either put in RNAiso Plus for total RNA isolation or fixed in Bouin's solution and embedded in paraffin for histological examination.

\section{RNA analysis by quantitative PCR}

Total RNA from tissues and cells was extracted using RNAiso Plus reagent. cDNAs were synthesized using ReverTra Ace qPCR RT Kit (Toyobo, Osaka, Japan) for subsequent real-time quantitative $\mathrm{PCR}$ analysis. The PCR reaction mixtures contained $10 \mathrm{ul} \mathrm{SYBR}{ }^{\circ}$ Premix Ex Taq II (Toyobo), 1 ul (0.5 pmole/ $\mu \mathrm{l})$ of each primer, 1 ul template cDNA, and 7 ul DNasefree water to a final volume of $20 \mathrm{ul}$. The conditions used for real-time quantitative PCR were as follows: $95{ }^{\circ} \mathrm{C}$ for $10 \mathrm{~s}$, followed by 45 cycles at $95{ }^{\circ} \mathrm{C}$ for $5 \mathrm{~s}$, $60^{\circ} \mathrm{Cfor} 30 \mathrm{~s}$, and $72{ }^{\circ} \mathrm{C}$ for $30 \mathrm{~s}$. The reaction was completed with a dissociation step for melting point analysis from $50{ }^{\circ} \mathrm{C}$ to $95{ }^{\circ} \mathrm{C}$ (in increments of $0.5{ }^{\circ} \mathrm{C}$ for $10 \mathrm{~s}$ each). All reactions were run in duplicate. Bactin was used as the reference gene. The RNA levels were calculated by the $2-\Delta C T$ method, where CT was the cycle threshold. Primer pairs specific for each gene were designed on the basis of the published sequences and are presented in Table 1.

\section{Histology}

Fixed ovaries and fat tissues were embedded in paraffin, and $5 \mu \mathrm{m}$ sections were cut and stained with hematoxylin and eosin (H\&E). The number of cystic follicles (with granulosa cells degenerated) and corpus luteum were counted in more than six slides. The diameters of adipocytes were determined using Image- Pro Plus 6.0.

\section{Granulosa cell culture}

21-day-old female C57BL/6 mice were injected i.p. with 5 IU of PMSG (ProSpec) to initiate follicular development. To stimulate ovulation and luteinization, mice were injected $48 \mathrm{~h}$ after PMSG injection with $5 \mathrm{IU}$ of hCG (Sigma) and then collected 7-12 h later. Mice were then euthanized by cervical dislocation, ovaries were removed, and fat and mesangial tissue around ovaries were removed using a $1 \mathrm{~mL}$ syringe with needle. Granulosa cells were obtained from the ovarian tissue by follicular puncture, and placed in PBS. The cell suspension was filtered through a 70 um mesh sieve three times to remove oocytes and centrifuged at $1000 \times \mathrm{g}$ for $5 \mathrm{~min}$. The pellet was resuspended in serum-free DMEM F12 containing 3\% BSA and insulin-transferrin-sodium selenite (ITS, Sigma). For in vitro analysis, granulosa cells were co-cultured with $10^{-3} \mathrm{nM}$ of the mTOR inhibitor rapamycin (Selleck). For groups receiving antibody treatment, $0.5 \mu \mathrm{g} / \mathrm{mL}$ mouse anti-GPR1 antibody (Zabel laboratory) was added. Control groups received $0.5 \mu \mathrm{g} /$ $\mathrm{mL}$ rat IgG (Abcam). Plates were incubated at $37^{\circ} \mathrm{C}, 5 \%$ $\mathrm{CO} 2$, and cells and media were collected after $24 \mathrm{~h}$. A CCK-8 assay (Beyotime, China) was employed to quantitatively evaluate cell proliferation. Media were analyzed for hormone levels by the Beijing North Biotechnology

Table 1 Primer pairs specific for each gene used in the study

\begin{tabular}{llll}
\hline Name & Fw Primer Sequence (5'-3') & Rv Primer Sequence (5'-3') & Target Sequence \\
\hline GnRH & gtggatcaaatggcagaaccc & gggccagtgcatctacatct & NM_008145.3 \\
AR & tccaagacctatcgaggagcg & gtgggcttgaggagaaccat & NM_013476.4 \\
ERA & cccgccttctacaggtctaat & NM_007956.5 \\
LH & tggccgcagagaatgagttc & cttctcgttactgctggacag & NM_008497.2 \\
FSH & ggagagcaatctgctgccata & ctcggaccatgctaggacagtag & NM_008045.3 \\
GH & ctacaaagagttcgagcgtgcctac & gcagaaacggcactcttcct & NM_008117.3 \\
PRL & agggagttgagaagataattagccag & caattccatgtcggttctctgc & NM_011164.2 \\
UCP1 & actgccacacctccagtcatt & aagaggagaccaattgcaccca & NM_009463.3 \\
StAR & ccgggtggatgggtcaa & ctttgcctcactcaggattgg & NM_011485.4 \\
P450sCC & ccatcagatgcagagtttccaa & cacctctccctgctggatgta & NM_019779.3 \\
3B-HSD & ggaggcctgtgttcaagcaa & tgagaagagtatcgacgcatcct & NM_008293.4 \\
17B-HSD & ttgttgggccgctagaag & ggccctgcaacatcaactg & NM_010475.1 \\
Aromatase & gcaatcctgaaggagatcca & cacccacagcgttcaattca & NM_007810.3 \\
Hsd17b7 & cctgtgctcagtccgtttt & gccgtcaattacgtcatcct & NM_010476.3 \\
\hline
\end{tabular}

Supplement: Internal Reference ßactin Fw,gtgacgttgacatccgtaaaga Rv,gccggactcatcgtactccTarget,NM_007393.5 
Research Institute, and cells were placed in RNAiso Plus and stored at $-80{ }^{\circ} \mathrm{C}$ for qPCR.

\section{Hormone measurements}

Serum testosterone, estradiol, and progesterone levels were measured using commercial iodine [125I] RIA Kits (Beijing North Biotechnology Research Institute). Serum HDL (High Density Lipoprotein), LDL (Low Density Lipoprotein), $\mathrm{CHO}$ (Cholesterol), and TG (Triglyceride) levels were measured using the cobas c311 automatic biochemical analyzer (Roche, Shenzhen SHAHE Hospital). The intra- and inter-assay errors among all assays were less than 10 and 15\%, respectively.

\section{Statistical analysis}

All data are presented as means \pm SEM. Statistical analysis of differences between two groups was performed using the Student's t-test; a $P$ value $<0.05$ was considered statistically significant. All analyses were performed using GraphPad Prism software (GraphPad Software Inc. , San Diego, CA, USA).

\section{Results}

Body weight gain and serum lipid and hormone levels

Body weight gains were significantly greater in DHEAtreated than in control wild type female mice. In Gpr1deficient mice, body weight gains were significantly greater than in wild type mice, but body weight gains in DHEA-treated Gpr1-deficient mice were less than those in both DHEA-treated wild type mice and untreated Gpr1-deficient mice (Fig. 1A), indicating that GPR1 may play a role in weight change and that Gpr1 deficiency suppresses DHEA-induced bodyweight gain.

Serum lipid and hormone levels were measured in control and DHEA-treated wild type and Gpr1-deficient mice. The serum lipid levels of wild type mice were not affected by DHEA, while in Gpr1-deficient mice, LDL levels were significantly elevated after DHEA treatment. $\mathrm{HDL}, \mathrm{CHO}$, and TG levels were not significantly different among the four groups (Fig. 1B).

Testosterone levels were significantly greater in both wild type and Gpr1 knockout mice after DHEA treatment than they were in the control mice, confirming proper establishment of the in vivo hyperandrogenism model. Gpr1 deficiency significantly elevated estradiol levels in both DHEA-treated and control mice (Fig. 1C).

\section{Relative mRNA expression for steroid receptors and} hormones in the hypothalamus and pituitary gland

To determine the effect of hyperandrogenism on the hypothalamic-pituitary-gonadal axis, we measured the levels of mRNAs encoding steroid receptors and GnRH (Gonadotropin Releasing Hormone) in the hypothalamus and those encoding several hormones in the pituitary glands of the four experimental groups.

Our data revealed DHEA treatment significantly suppressed AR (androgen receptor) mRNA levels in Gpr1 knockout mice. ER-A (Estrogen receptor A) and GnRH mRNA levels were lower in Gpr1 knockout mice than in wild type controls (Fig. 2A).

In pituitary glands, $L H$ (Luteinizing Hormone) mRNA levels were lower, and GH (Growth Hormone) mRNA levels were higher in DHEA-treated control wild type mice. In Gpr1 knockout mice, the levels of $L H$ mRNA were also lower in the DHEA-treated cohort, while the levels of FSH (Follicle-Stimulating Hormone) and PRL (Prolactin) mRNAs were significantly higher in DHEAtreated Gpr1 knockout mice than in DHEA-treated wild type mice (Fig. 2B).

Variation in the relative levels of $G H$ mRNA was in accordance with variation in bodyweight gain; Gpr1 deficiency suppressed DHEA-induced increase in relative GH mRNA expression. Gpr1 deficiency also significantly increased the levels of $F S H$ and PRL mRNAs, whether mice were treated with DHEA or not. Since FSH promotes follicular development and PRL is important for the maintenance and secretory activity of the corpus luteum [32], GPR1 may play a regulatory role in the biosynthesis of ovarian hormones.

\section{Adipose tissue morphology and expression of mRNAs for steroid receptors}

At the end of DHEA treatment, the sizes of scapular, mesenteric, inguinal, and gonadal adipocytes were measured in hematoxylin and eosin (HE)-stained sections from control and DHEA-treated wild type and knockout mice. In each group, the diameters of adipocytes were measured in three randomly selected sections per fat depot per mouse.

Our results indicate increased diameters of adipocytes in scapular brown adipose tissue (BAT) but decreased in mesenteric, inguinal, and gonadal adipocytes after DHEA treatment in wild type mice. While in Gpr1 knockout mice, the diameters were significantly decreased in scapular, but increased in mesenteric, inguinal, and gonadal adipocytes after DHEA treatment when compared with DHEA treated wild type mice. Indicating that loss of Gpr1 attenuated the effect of DHEA on both brown and white adipose tissues (WAT) (Fig. 3A).

Gpr1 deficiency significantly elevated Ucp1 (Uncoupling Protein-1) mRNA abundance, especially with DHEA treatment (Fig. 3B), indicating that GPR1 may play a role in estradiol biosynthesis and thermogenesis in brown adipose tissue.

In mesenteric adipose tissue, the relative levels of $A R$ mRNA were significantly lower in the DHEA-treated Gpr1 knockout mice than in the DHEA-treated wild 


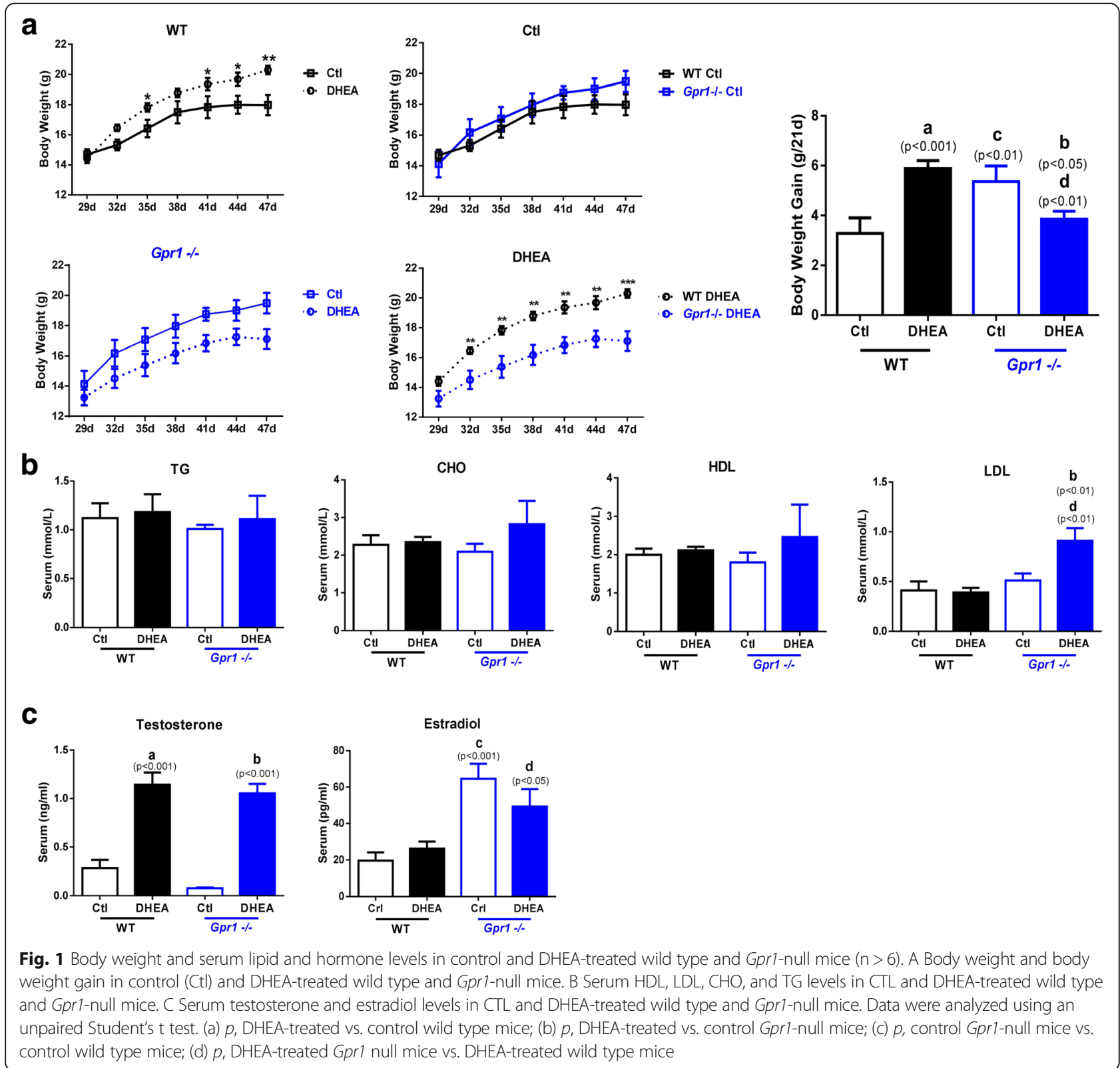

type mice (Fig. 3C). But for both four kinds of adipose tissues we collected, relative levels of ERA mRNA were lower in DHEA-treated Gpr1 knockout mice than in DHEA-treated wild type mice (Fig. 3B, C, D, E). Which indicating that GPR1 deficiency may attenuated the respond of mesenteric adipose tissue to androgen and the respond of both four adipose tissues to estradiol after DHEA treatment.

\section{Ovarian features and expression of mRNAs for steroid synthesis enzymes}

To determine the effects of DHEA on ovaries, ovaries were sectioned and stained with hematoxylin and eosin. DHEA treatment of wild type mice resulted in an increase in the number of cystic follicles with degenerated granulosa cells and an absence of corpus luteum. The numbers of antral and pre-antral follicles were increased with arrangement typical of that in polycystic ovaries. The ovaries of Gprl-deficient mice contained follicles at different stages of maturation, with more corpus luteum and mesenchyme. However, ovaries of DHEA-treated Gpr1-deficient mice contained still greater numbers of cystic follicles but fewer small follicles than ovaries from DHEA-treated wild type mice, and corpus luteum reoccurred (Fig. 4A).

Then we further investigated mRNA expression for steroid synthesis enzymes in the ovaries of the four experimental groups. The results showed that DHEA 


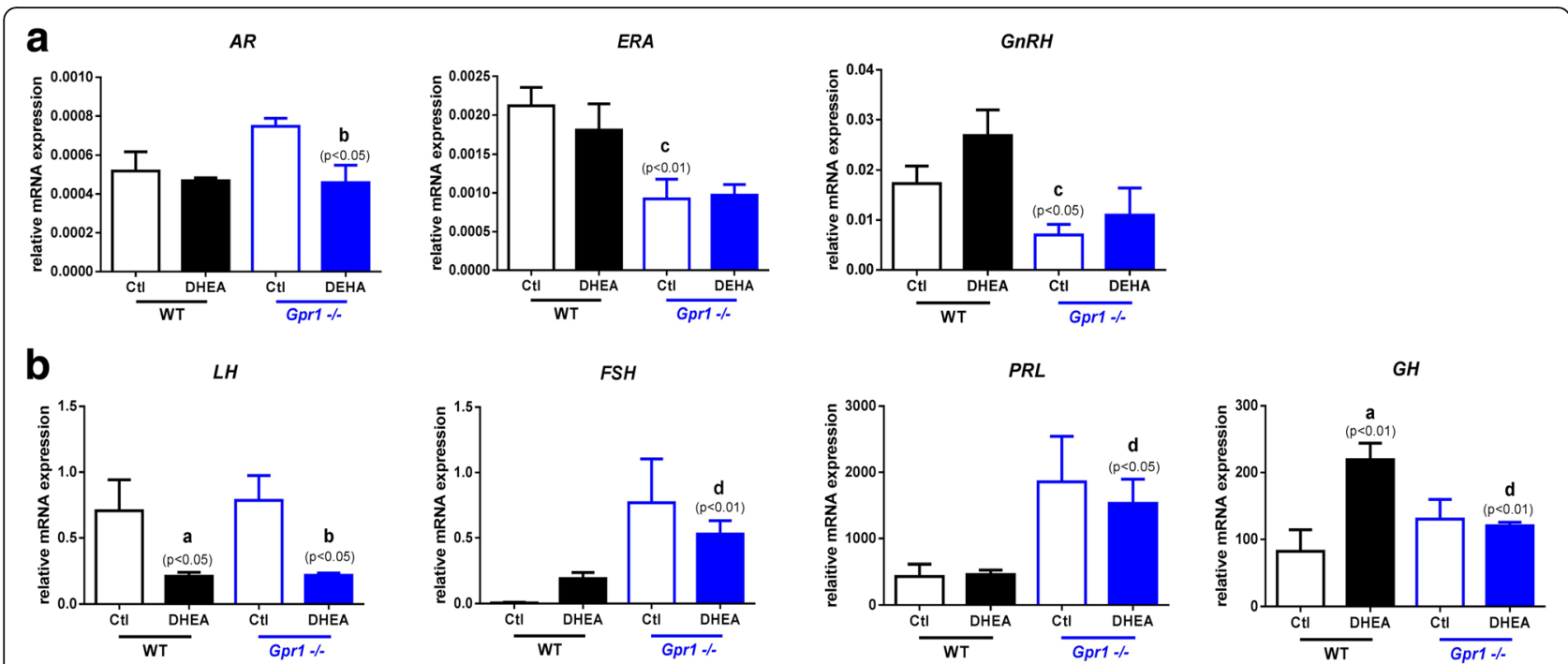

Fig. 2 Relative mRNA expression levels in the hypothalamus and pituitary gland in CTL and DHEA-treated wild type and Gpr1-null mice ( $n>6)$. A Expression of mRNA for steroid receptors and GnRH in hypothalamus of CTL and DHEA-treated wild type and Gpr1-null mice. B Expression of LH, FSH, PRL and GH mRNAs in pituitary glands of CTL and DHEA-treated wild type and Gpr1-null mice. Data were analyzed using an unpaired Student's $t$ test. (a) $p$, DHEA-treated vs. control wild type mice; (b) p, DHEA-treated vs. control Gpr1-null mice; (c) p, control Gpr1-null mice vs. control wild type mice; (d) p, DHEA-treated Gpr1 null mice vs. DHEA-treated wild type mice

treatment significantly reduced the abundance in ovaries of mRNAs for StAR (Steroidogenic Acute Regulatory Protein), P450scc (Cytochrome P450), 3B-HSD (3ß-Hydroxysteroid Dehydrogenase) and HSD17B7 (Hydroxysteroid 17-Beta Dehydrogenase 7) in wild type mice, while the tendency could be all attenuated in Gpr1-deficient mice (Fig. 4B).

Role of mTOR signaling in DHEA-induced, GPR1-mediated ovarian granulosa cell estradiol biosynthesis in vitro To investigate the mechanism of DHEA-induced, GPR1-mediated estradiol secretion, ovarian granulosa cells were isolated and treated with DHEA or vehicle in the presence of anti-GPR1 antibody or a control antibody, and both cell proliferation and estradiol levels in the conditioned media were measured. We found that the proliferation of granulosa cells was elevated after DHEA treatment when anti-GPR1 antibody was added (Fig. 5A). Estradiol levels were increased in the media from cells treated with either DHEA or GPR1 antibody alone, but GPR1 antibody attenuated the DHEA-induced increase in estradiol (Fig. 5B).

We then isolated cellular RNA and measured the levels of mRNAs for two key enzymes involved in estradiol secretion -Aromatase and HSD17B7 - and found that both were significantly increased in the presence of GPR1 antibody, regardless of whether or not the cells were treated with DHEA. These results are in accordance with measurements of serum estradiol levels (Fig. 5C).
To further explore the pathways involved in DHEAinduced, GPR1-mediated estradiol synthesis, we blocked multiple signaling pathways using specific inhibitors, including the PI3K inhibitor wortmannin (Selleck), the PKC inhibitor Sotrastaurin (Selleck), the AKT inhibitor MK-2206 $2 \mathrm{HCl}$ (Selleck) (data not shown), and the mTOR inhibitor rapamycin (Selleck) and measured mRNA levels for estradiol synthesis-related enzymes. Inhibition of mTOR with rapamycin caused Aromatase mRNA levels to increase in the groups treated with control IgG, with or without DHEA treatment, and HSD17B7 mRNA levels to increase in cells treated with DHEA and control IgG. In the GPR1 antibody group, the mTOR inhibitor suppressed the expression of Aromatase and HSD17B7 mRNAs. The DHEA-induced increases in Aromatase and HSD17B7 mRNA levels in the IgG group were attenuated by GPR1 antibody (Fig. 5D).

\section{Discussion}

DHEA-induced hyperandrogenemia in mice exhibits some of the phenotypes of PCOS, such as elevated body weight and serum testosterone levels, increased numbers of small follicles, and abnormal steroidogenesis. Since serum Chemerin levels are reported to be higher in women with PCOS [25], and as we previously documented a relationship between the Chemerin receptor CMKLR1 and DHT-induced PCOS in mice, we were curious about whether GPR1, another Chemerin receptor, was also involved in steroid synthesis in hyperandrogenemic mice.

Our examination of systemic indicators revealed that GPR1 deficiency suppresses DHEA-induced body 


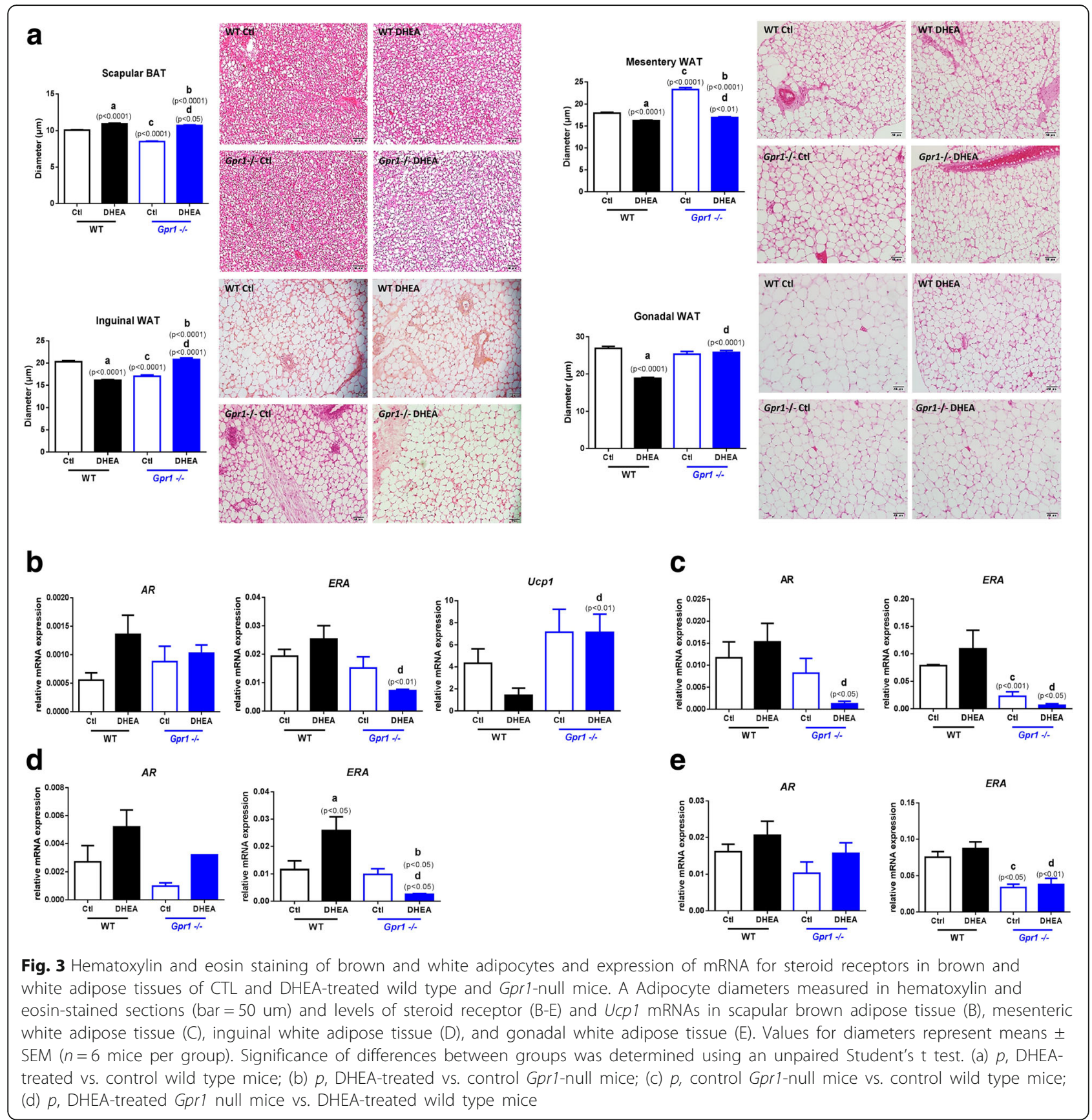

weight gain, significantly increases serum LDL levels in mice treated with DHEA, and sharply increases serum estradiol levels with or without DHEA treatment. Since obesity is a major characteristic of PCOS [33] and LDL is the major source of cholesterol, a precursor for steroid biosynthesis [34], GPR1 could play a role in both weight change and steroid biosynthesis. However, whether or not change in body weight is caused by changes in fat mass, elevated estradiol levels are caused by the conversion of DHEA or the regulatory effect of GPR1 in the secretion of estrogen during follicular development need further analysis.

To investigate the role of GPR1 in DHEA-induced changes in body weight, samples of brown adipose tissue and of white adipose tissues from three different sites were isolated, and the diameters of adipocytes and alterations in relative gene expression were measured. Our data showed that DHEA treatment increased brown adipocyte diameters but decreased white adipocyte diameters. Decreased white adipocyte diameters, in combination with increased body weight, may result from effects of DHEA 

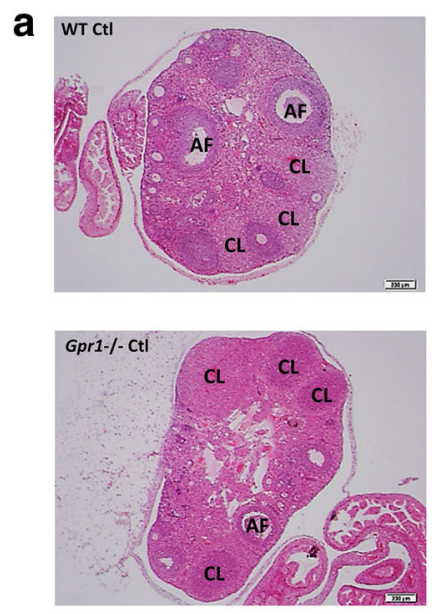

b
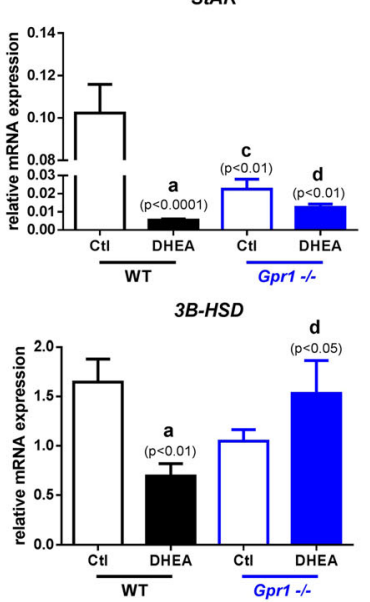
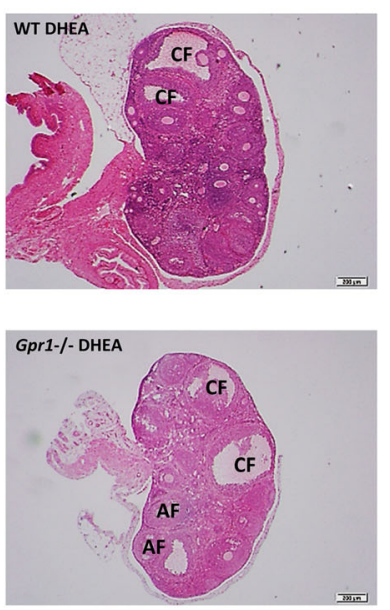

P450scc

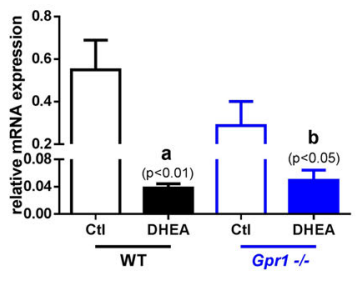

17B-HSD

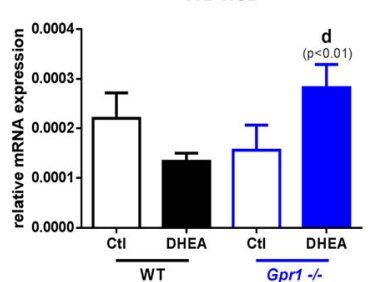

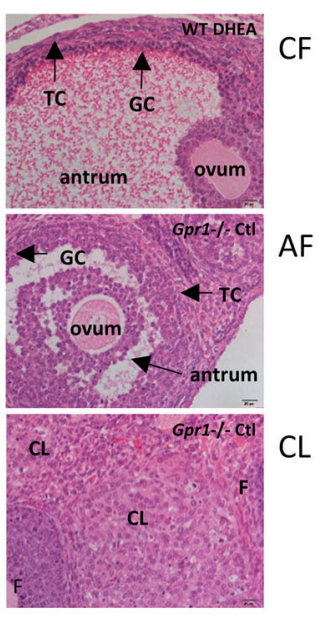

Aromatase

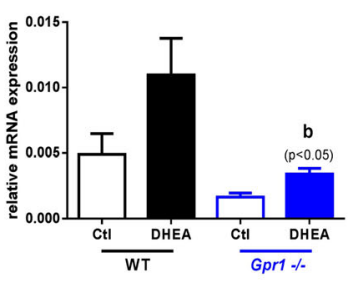

HSD17B7

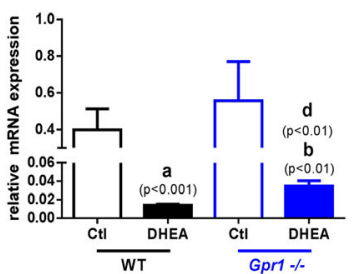

Fig. 4 Ovarian features and expression of mRNAs for steroid synthesis enzymes in CTL and DHEA-treated wild type and Gpr1-null mice. A Hematoxylin and eosin staining of CTL and DHEA-treated ovaries was examined. The high magnification images on the right show the difference of ovary morphology among various treatment groups. AF, antral follicle. CL, corpus luteum. CF, Cystic follicle. TC, theca cell. GC, granulosa cell. F, follicle. Data represent means \pm SEM. Bar $=200 \mu \mathrm{m}$. B Expression of mRNA for steroid synthesis enzymes in CTL and DHEA-treated wild type and Gpr1-null mice. Data were analyzed by an unpaired Student's $t$ test. (a) $p$, DHEA-treated vs. control wild type mice; (b) p, DHEA-treated vs. control Gpr1-null mice; (c) p, control Gpr1-null mice vs. control wild type mice; (d) p, DHEA-treated Gpr1 null mice vs. DHEA-treated wild type mice

on metabolism, such as impairment of fat synthesis and the promotion of fat-free tissue deposition and resting heat production [35]. Gpr1 deficiency could attenuate DHEA-induced changes in both brown and white adipocytes. Relative expression of $E R A$ mRNA was reduced in scapular, mesenteric, inguinal, and gonadal fat in Gpr1-deficient mice treated with DHEA. Since adipocytes are the targets of estrogen, estrogen and its receptor could affect adipocyte differentiation, promoting lipolysis and inhibiting lipid synthesis, thereby reducing the deposition of fat [36]. DHEA could be converted to estradiol and activate ERA [37], while Gpr1 deficiency could attenuate that activation. In addition, the levels of $U c p 1$ mRNA in brown adipocytes were significantly elevated in Gpr1-deficient mice treated with DHEA, indicating the recovery of heat produced in response to DHEA treatment.
The hypothalamus-pituitary axis is a complex functional system involving both neural and endocrine components. The pituitary secretion of LH and FSH is stimulated by $\mathrm{GnRH}$, further regulating steroid synthesis in ovaries and fat tissues [38].

Steroid synthesis and secretion play an important role in follicular development. To investigate the role of GPR1 in ovarian steroid synthesis, we measured the levels of key limiting steroid synthetic enzymes, including StAR, which regulates the transport of cholesterol [39], P450scc, a key enzyme in the conversion of cholesterol to pregnenolone [40], Aromatase, which catalyzes the conversion of androgens to estrogens [41], $3 B-H S D$, which converts pregnenolone to progesterone [42], 17B-HSD (17 $\beta$-Hydroxysteroid Dehydrogenase), which converts androgens to estrogens [43], HSD 17B7, which is proposed to regulate the balance 
a

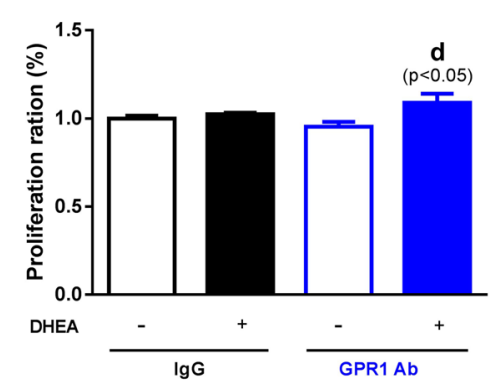

C

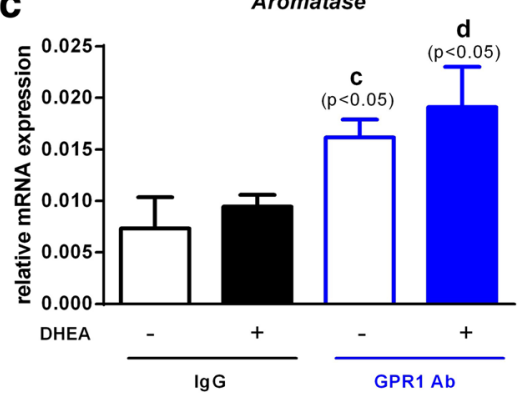

d

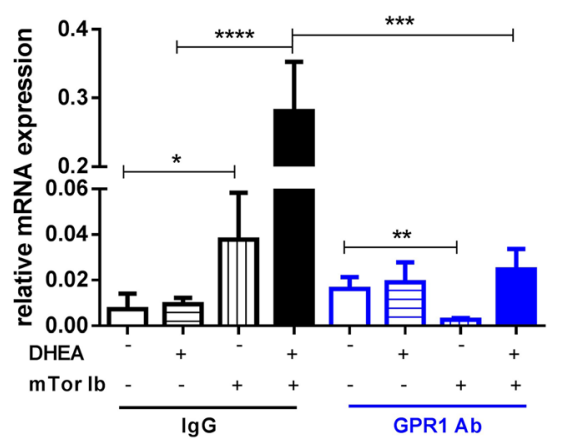

b

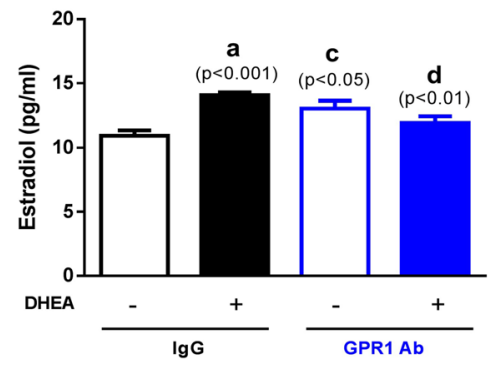

HSD17B7

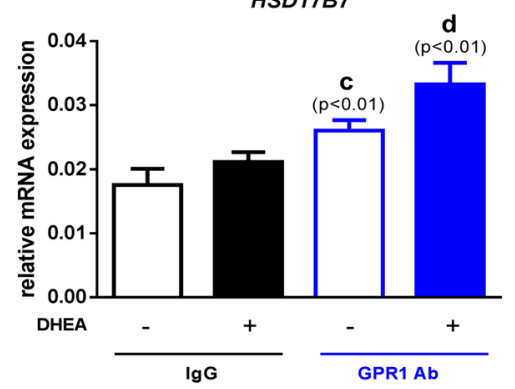

HSD17B7

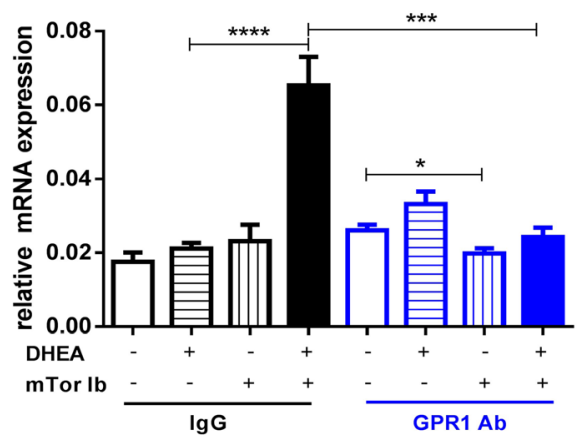

Fig. 5 Granulosa cells were isolated after PMSG treatment for $48 \mathrm{~h}$ and $\mathrm{hCG}$ treatment for $7-12 \mathrm{~h}$ and further treated under different conditions for 24 h. A Cell Proliferation under different conditions. B Estradiol levels in culture media from cells under different conditions. C, D Relative mRNA levels for Aromatase and HSD17B7 in granulosa cells under different conditions. Data were analyzed by an unpaired Student's t test. (a) $p$, DHEA-treated vs. control IgG group; (b) $p$, DHEA-treated vs. control GPR1 antibody group; (c) $p$, control GPR1 antibody group vs. control IgG group; (d) $p$, DHEA-treated GPR1 antibody group vs. DHEA-treated IgG group. $\left({ }^{*} p<0.05 ;{ }^{* *} p<0.01\right.$; $\left.{ }^{* * *} p<0.001 ;{ }^{* * *} p<0.0001\right)$

of E2 and DHT [44], an enzyme that functions as a $17 B-$ $H S D$ in the biosynthesis of sex steroids [45].

In mice treated with DHEA, we found that Gpr1 deficiency could attenuate the reduction in levels of steroidogenesis-related enzymes in ovaries. These results indicate that Gpr1 deficiency may, to some extent, enable the improvement of the abnormal hormone synthesis induced by DHEA. In particular, Gpr1 deficiency has a tendency to suppress the DHEA-induced elevation in Aromatase mRNA expression in ovaries. Since the aromatase inhibitor letrozole has already been shown to be an effective therapeutic drug for PCOS [46, 47], GPR1 may be useful as an alternative or adjunct target for PCOS therapy.
To further explore the mechanism of DHEA-induced, GPR1-mediated estradiol secretion, ovarian granulosa cells were isolated and cultured in vitro and the effect of blocking GPR1 function on DHEA induction of estradiol secretion was examined. We found that estradiol levels were elevated after DHEA treatment. Interestingly, even though estradiol levels were also increased by treatment with anti-GPR1 antibody, anti-GPR1antibody and DHEA treatment together led to estradiol levels below that of either treatment alone. From our data, we infer that Gpr1 deficiency partially attenuates the DHEA-induced increase in estradiol secretion and that it does so through the mTOR signaling pathway to affect key enzymes involved in estradiol synthesis (Fig. 6b). 


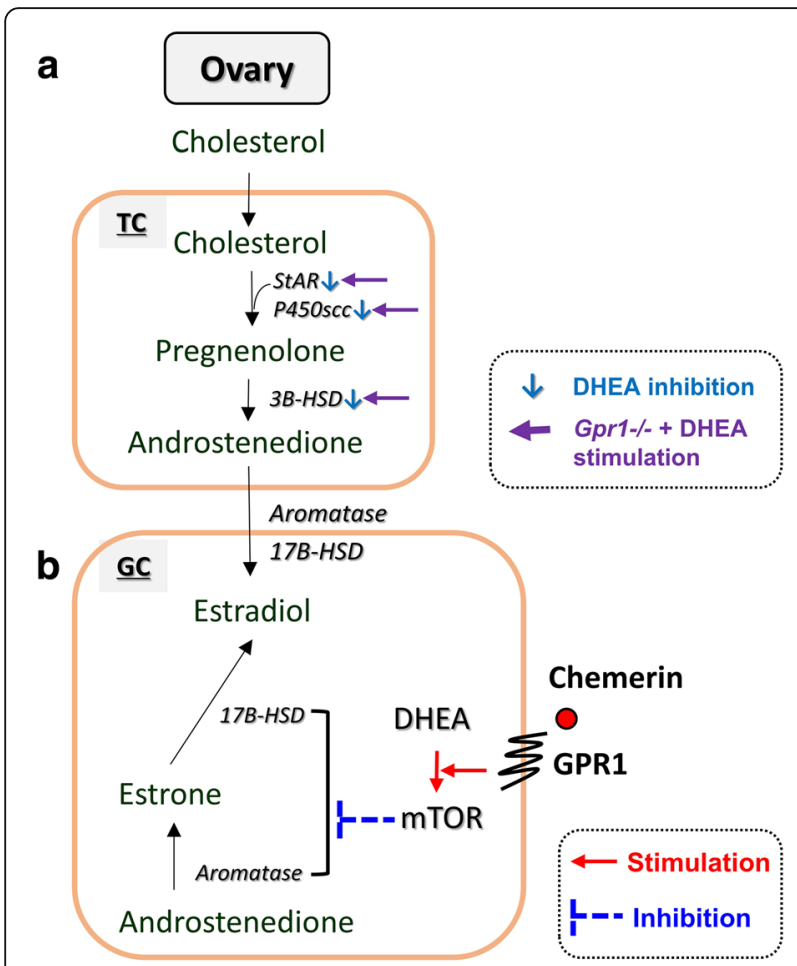

Fig. 6 Gpr1 deficiency attenuates the effect of DHEA and Chemerin/ GPR1 signaling modulates estradiol biosynthesis in granulosa cells with DHEA treatment through the mTOR signaling pathway. a DHEA treatment led to decreased ovarian steroidogenesis. Gprl deficiency improved steroidogenesis in ovaries. b Chemerin/GPR1 signaling modulates elevated estradiol secretion induced by DHEA through the mTOR signaling pathway to affect key enzymes involved in estradiol synthesis

\section{Conclusions}

In conclusion, our study for the first time demonstrates a regulatory role for the Chemerin-GPR1 pathway in DHEAinduced hyperandrogenism in mice. Since the interaction between organs in the endocrine system is complex, more studies are needed to fully understand the relationships between signals and pathways. However, our findings show that Gprl deficiency can attenuated the negative effects of DHEA, including the increases in body weight and improve steroidogenesis in ovaries (Fig. 6a). Our results indicate that GPR1 could be a new therapeutic target for the treatment of DHEA-induced hyperandrogenism.

\section{Additional file}

Additional file 1: Figure S1. Validation for Gpr1 knockout mice. Figure on the left is the reproduction and selection of our Gpr1 knockout mice. Figure on the right is the genotyping of our Gpr1 knockout mice. (TIF $14703 \mathrm{~kb}$ )

\section{Abbreviations}

17B-HSD: 17ß-Hydroxysteroid Dehydrogenase; 3B-HSD: 3ß-Hydroxysteroid Dehydrogenase; AR: Androgen Receptor; BAT: Brown Adipose Tissue;
CHO: Cholesterol; DHEA: Dehydroepiandrosterone; ER: Estrogen Receptor; FSH: Follicle-Stimulating Hormone; GC: Granulosa Cell; GH: Growth Hormone; GnRH: Gonadotropin Releasing Hormone; HDL: High Density Lipoprotein; HSD17B7: Hydroxysteroid 17-Beta Dehydrogenase 7; LDL: Low Density Lipoprotein; LH: Luteinizing Hormone; P450scc: Cytochrome P450; PCOS: Polycystic Ovary Syndrome; PRL: Prolactin; StAR: Steroidogenic Acute Regulatory Protein; TC: Thecal Cell; TG: Triglyceride; UCP-1: Uncoupling Protein-1; WAT: White Adipose Tissue

\section{Acknowledgments}

We acknowledge the assistance of Matt Petitt in improving the English grammar, particularly syntax of the manuscript.

\section{Funding}

This study was supported by the Strategic Priority Research Program of CAS (XDA16020702), This study was supported by the National Natural Science Foundation of China (81771611 and 31671562), Guangdong Natural Science Foundation (2017A020211033), the Science and Technology Innovation Fund of Shenzhen (JCYJ20170413165233512, JCYJ20170412140326739,

JCYJ20170413165503382, JCYJ20170815123502541, JCYJ20170814175916411, and JCYJ20170307165601938), 2013B021800095 to HRT, and JCYJ20140415162338852 to HRT.

\section{Availability of data and materials}

Please contact corresponding author for data requests.

\section{Authors' contributions}

JVZ and YLY conceived and designed the experiments; LFS, BBW, TXX and PGR performed the experiments; YLY, LFS, and YY analyzed the data; YY, PGR and HRT contributed reagents/materials/analysis tools/housing animals; YLY, JVZ, and HRT wrote and revised the manuscript. All authors read and approved the final manuscript.

\section{Ethics approval}

Experimental protocols using mice were approved by the Committee on the Use of Live Animals for Teaching and Research, Shenzhen Institutes of Advanced Technology, Chinese Academy of Sciences.

\section{Competing interests}

The authors declare that they have no competing interests.

\section{Publisher's Note}

Springer Nature remains neutral with regard to jurisdictional claims in published maps and institutional affiliations.

\section{Author details}

${ }^{1}$ Research Laboratory for Reproductive Health, Shenzhen Institutes of Advanced Technology, Chinese Academy of Sciences, Shenzhen 518055, China. ${ }^{2}$ University of Chinese Academy of Sciences, Beijing 100049, China. ${ }^{3}$ Baoan Maternal and Child Health Care Hospital, Shenzhen 518101, China.

${ }^{4}$ Peking University Shenzhen Hospital, Shenzhen 518035, China.

Received: 3 February 2018 Accepted: 29 April 2018

Published online: 24 May 2018

\section{References}

1. Jr PC. Dehydroepiandrosterone and dehydroepiandrosterone sulfate production in the human adrenal during development and aging. Steroids. 1999:64(9):640.

2. Majewska MD. Neuronal actions of dehydroepiandrosterone. Possible roles in brain development, aging, memory, and affect. Ann N Y Acad Sci. 2010; 774(1):111-20

3. Wolkowitz OM, Reus VI, Roberts E, Manfredi F, Chan T, Raum WJ, Ormiston S, Johnson R, Canick J, Brizendine L. Dehydroepiandrosterone (DHEA) treatment of depression. Biol Psychiatry. 1997;41(3):311

4. Oberbeck R, Deckert H, Bangen J, Kobbe P, Schmitz D. Dehydroepiandrosterone: a modulator of cellular immunity and heat shock protein 70 production during polymicrobial sepsis. Intensive Care Med. 2007;33(12):2207-13.

5. Chen J, Tang X, Zhang Y, Ma H, Zou S. Effects of maternal treatment of dehydroepiandrosterone (DHEA) on serum lipid profile and hepatic lipid 
metabolismrelated gene expression in embryonic chickens. Comp Biochem Physiol Part B. 2010;155(4):380.

6. Ahmed HH, Morcos NYS, Eskander EF, Seoudi DMS, Shalby AB. Role of dehydroepiandrosterone in management of glucocorticoid-induced secondary osteoporosis in female rats. Exp Toxicol Pathol. 2012;64(6):659-64.

7. Savineau JP, Marthan R, Dumas dl RE. Role of DHEA in cardiovascular diseases. Biochem Pharmacol. 2013;85(6):718-26.

8. Belgorosky D, Sander VA, Yorio MP, Faletti AG, Motta AB. Hyperandrogenism alters intraovarian parameters during early folliculogenesis in mice. Reprod BioMed Online. 2010;20(6):797-807.

9. Chen D, Kang J, Haitian MA. Effect of different dose of DHEA on lipid metabolism in SD rats with high-fat diet. Biochem J. 2015;228(3):673-81.

10. Loughlin T, Cunningham S, Moore A, Culliton M, Smyth PP, Mckenna TJ. Adrenal abnormalities in polycystic ovary syndrome. J Clin Endocrinol Metab. 1986;62(1):142-7.

11. Goodarzi MO, Enrico C, Ricardo A. DHEA, DHEAS and PCOS. J Steroid BiochemMol Biol. 2015;145:213-25.

12. Bates GW, Legro RS. Longterm management of polycystic ovarian syndrome (PCOS). Mol Cell Endocrinol. 2013;373(1-2):91-7.

13. Beloosesky R, Gold R, Almog B, Sasson R, Dantes A, Land-Bracha A, Hirsh L, Itskovitz-Eldor J, Lessing JB, Homburg R. Induction of polycystic ovary by testosterone in immature female rats: modulation of apoptosis and attenuation of glucose/insulin ratio. Int J Mol Med. 2004;14(2):207-15.

14. Chapman JC, Min SH, Freeh SM, Michael SD. The estrogen-injected female mouse: new insight into the etiology of PCOS. Reprod Biol Endocrinol. 2009; $7(1): 47$

15. Kafali H, Iriadam M, Ozardali I, Demir N. Letrozole-induced polycystic ovaries in the rat: a new model for cystic ovarian disease. Arch Med Res. 2004:35(2):103.

16. Zheng Q, Li Y, Zhang D, Cui X, Dai K, Yang Y, Liu S, Tan J, Yan Q. ANP promotes proliferation and inhibits apoptosis of ovarian granulosa cells by NPRA/PGRMC1/EGFR complex and improves ovary functions of PCOS rats. Cell Death Dis. 2017;8(10):e3145.

17. Ressler IB, Grayson BE, Seeley RJ. Metabolic, behavioral and reproductive effects of vertical sleeve gastrectomy in an obese rat model of polycystic ovary syndrome. Obes Surg. 2014;24(6):866-76

18. Patisaul HB, Mabrey N, Adewale HB, Sullivan AW. Soy but not bisphenol a (BPA) induces hallmarks of polycystic ovary syndrome (PCOS) and related metabolic co-morbidities in rats. Reprod Toxicol. 2014;49:209-18.

19. Wilson JL, Chen W, Dissen GA, Ojeda SR, Cowley MA, Garcia-Rudaz C, Enriori PJ. Excess of nerve growth factor in the ovary causes a polycystic ovary-like syndrome in mice, which closely resembles both reproductive and metabolic aspects of the human syndrome. Endocrinology. 2014;155(11): 4494-506.

20. van Houten EL, Visser JA. Mouse models to study polycystic ovary syndrome: a possible link between metabolism and ovarian function? Reprod Biol. 2014;14(1):32-43.

21. Maurya VK, Sangappa C, Kumar V, Mahfooz S, Singh A, Rajender S, Jha RK. Expression and activity of Rac1 is negatively affected in the dehydroepiandrosterone induced polycystic ovary of mouse. J Ovarian Res. 2014;7(1):32.

22. Elia E, Sander V, Luchetti CG, Solano ME, Di GG, Gonzalez C, Motta AB. The mechanisms involved in the action of metformin in regulating ovarian function in hyperandrogenized mice. Mol Hum Reprod. 2006;12(8):475.

23. Solano ME, Sander VA, Ho H, Motta AB, Arck PC. Systemic inflammation, cellular influx and up-regulation of ovarian VCAM-1 expression in a mouse model of polycystic ovary syndrome (PCOS). J Reprod Immunol. 2011;92(1-2):33

24. Bondue B, Wittamer V, Parmentier M. Chemerin and its receptors in leukocyte trafficking, inflammation and metabolism. Cytokine Growth Factor Rev. 2011;22(5-6):331.

25. Tan BK, Chen J, Farhatullah S, Adya R, Kaur J, Heutling D, Lewandowski KC, O'Hare JP, Lehnert H, Randeva HS. Insulin and metformin regulate circulating and adipose tissue chemerin. Diabetes. 2009;58(9):1971-7.

26. Li L, Ma P, Huang C, Liu Y, Zhang Y, Gao C, Xiao T, Ren PG, Zabel BA, Zhang $\mathrm{JV}$. Expression of chemerin and its receptors in rat testes and its action on testosterone secretion. J Endocrinol. 2014;220(2):155-63.

27. Zabel BA, Nakae S, Zúñiga L, Kim JY, Ohyama T, Alt C, Pan J, Suto H, Soler D, Allen SJ. Mast cell-expressed orphan receptor CCRL2 binds chemerin and is required for optimal induction of $\mathrm{lgE}$-mediated passive cutaneous anaphylaxis. J Exp Med. 2008;205(10):2207.
28. Rourke JL, Dranse HJ, Sinal CJ. CMKLR1 and GPR1 mediate chemerin signaling through the RhoA/ROCK pathway. Mol Cel Endocrinol. 2015: 417(C):36-51.

29. Tang $M$, Huang $C$, Wang $Y F$, Ren $P G$, Chen $L$, Xiao TX, Wang BB, Pan YF, Tsang BK, Zabel BA. CMKLR1 deficiency maintains ovarian steroid production in mice treated chronically with dihydrotestosterone. Sci Rep. 2016;6:21328.

30. Rourke JL, Muruganandan S, Dranse HJ, Mcmullen NM, Sinal CJ. Gpr1 is an active chemerin receptor influencing glucose homeostasis in obese mice. J Endocrinol. 2014;222(2):201.

31. Yang $Y L$, Ren $L R$, Sun LF, Huang C, Xiao TX, Wang BB, Chen J, Zabel BA, Ren P, Zhang JV. The role of GPR1 signaling in mice corpus luteum. J Endocrinol. 2016;230(1):55-65.

32. Freeman ME, Kanyicska B, Lerant A, Nagy G. Prolactin: structure, function, and regulation of secretion. Physiol Rev. 2000;10(80):1524-85.

33. Barber TM, Dimitriadis GK, Avgi A, Stephen F. Polycystic ovary syndrome: insight into pathogenesis and a common association with insulin resistance. Clin Med. 2016;16(3):262-6.

34. Diamantikandarakis E, Argyrakopoulou G, Economou F, Kandaraki E, Koutsilieris M. Defects in insulin signaling pathways in ovarian steroidogenesis and other tissues in polycystic ovary syndrome (PCOS). J Steroid Biochem Mol Biol. 2008:109(3-5):242-6.

35. Tagliaferro AR, Davis JR, Truchon S, Van HN. Effects of dehydroepiandrosterone acetate on metabolism, body weight and composition of male and female rats. J Nutr. 1986;1 16(10):1977-83.

36. Pedersen SB, Kristensen $\mathrm{K}$, Hermann PA, Katzenellenbogen JA, Richelsen B. Estrogen controls lipolysis by up-regulating alpha2A-adrenergic receptors directly in human adipose tissue through the estrogen receptor alpha. Implications for the female fat distribution. J Clin Endocrinol Metab. 2004; 89(4):1869-78.

37. Miller KK, Al-Rayyan N, Ivanova MM, Mattingly KA, Ripp SL, Klinge CM, Prough RA. DHEA metabolites activate estrogen receptors alpha and beta. Steroids. 2013;78(1):15-25.

38. U. Klenke, Gonadal and steroid feedback regulation of the hypothalamuspituitary axis in striped bass (Morone saxatilis), Dissertations \& Theses Gradworks (2006)

39. Stocco DM. A StAR search: implications in controlling steroidgenesis. Biol Reprod. 1997;56(2):328-36.

40. Kim YC, Ariyoshi N, Artemenko I, Elliott ME, Bhattacharyya KK, Jefcoate CR. Control of cholesterol access to cytochrome P450scc in rat adrenal cells mediated by regulation of the steroidogenic acute regulatory protein. Steroids. 1997;62(1):10

41. Morishima A, Grumbach MM, Simpson ER, Fisher C, Qin K. Aromatase deficiency in male and female siblings caused by a novel mutation and the physiological role of estrogens. J Clin Endocrinol Metab. 1995 ;80(12):3689-98.

42. Mcbride MW, Mcvie AJ, Burridge SM, Brintnell B, Craig N, Wallace AM, Wilson RH, Varley J, Sutcliffe RG. Cloning, expression, and physical mapping of the 3beta-hydroxysteroid dehydrogenase gene cluster (HSD3BP1HSD3BP5) in human. Genomics. 1999:61(3):277-84.

43. Labrie F, Luu-The V, Lin SX, Claude L, Simard J, Breton R, Bélanger A. The key role of $17 \beta$-hydroxysteroid dehydrogenases in sex steroid biology. Steroids. 1997;62(1):148.

44. Wang X, Gérard C, Thériault JF, Poirier D, Doillon CJ, Lin SX. Synergistic control of sex hormones by 17ß-HSD type 7: a novel target for estrogendependent breast cancer. J Mol Cell Biol. 2015;7(6)

45. Marijanovic Z, Laubner D, Moller G, Gege C, Husen B, Adamski J, Breitling R. Closing the gap: identification of human 3-ketosteroid reductase, the last unknown enzyme of mammalian cholesterol biosynthesis. Mol Endocrinol. 2003;17(9):1715

46. Mitwally MF, Casper RF. Use of an aromatase inhibitor for induction of ovulation in patients with an inadequate response to clomiphene citrate. Fertil Steril. 2001;75(2):305-9.

47. Mitwally MF, Casper RF. Aromatase inhibition for ovarian stimulation: future avenues for infertility management. Curr Opin Obstet Gynecol. 2002;14(3): 255-63. 